anteriorly by the free border of the epiglottis. The length of the larynx was $\sim 4-5 \mathrm{~mm}$. The cricoid cartilage formed a complete ring at the inferior aspect of the larynx and was fixed to the tracheal rings. The trachea was entered after passing through the cricoid cartilage and ended at the division into the right and left main stem bronchi at the carina. The bronchoscope was introduced through the larynx and directed to the trachea. The length and internal diameter of the trachea was $\sim 25-27 \mathrm{~mm}$ and 3-4 mm, respectively. The angle between the longitudinal axis of the trachea and the bifurcation of the main bronchi was approximately $15-17^{\circ}$. The angle of the right main bronchus was only slightly less than that of the left main bronchus. Once the trachea was entered, the tip of the bronchoscope was gently slid along the right and left lateral wall of the trachea. This manoeuvre allowed both the right and left main bronchi to be entered easily. In addition, to enter the right and left main bronchi, the rat's head was turned and flexed slightly to the ipsilateral side and the proximal portion of the bronchoscope moved toward the contralateral corner of the mouth. The main stem bronchi was $\sim 6-7 \mathrm{~mm}$ in length and its internal diameter was $2-3 \mathrm{~mm}$. The tip of the bronchoscope was advanced $4-5 \mathrm{~mm}$ into the right and left main bronchi. At this point, the distal progression of the instrument was halted. Overall, these attempts provided convincing results on proceeding tracheobronchial endoscopy. Thus, we strongly believe that our "simulated bronchoscopy" had the main physical properties of a rigid bronchoscope. The rat airway was not visualised in these experiment, yet, we think that this would not have changed the pathophysiological sequence leading to bacterial translocation following bronchoscopy.

There may some reports indicating that rigid bronchoscopy does not impair ventilation and oxygenation [2]. However, what about clinical studies that do show that rigid bronchoscopy induces alterations in arterial blood gases, including hypoxaemia, respiratory acidosis and hypercarbia [3-5]? GODDEN et al. [3] measured serial arterial blood gases in 10 patients during rigid bronchoscopy and showed carbon dioxide retention in nine patients even though ventilation was adequate in all. MATHISEN and GRILlo [4] observed 19 complications of 56 patients after rigid bronchoscope, in whom two of those complications were hypoxia and/or hypercarbia. It may intuitively appear that associated procedures during rigid bronchoscopy will increase resistance to ventilation and result in derangements in oxygenation [6]. Overall, can we insist that rigid bronchoscopy is a $100 \%$ safe procedure regarding alterations of arterial blood gas parameters?
As mentioned above, at the beginning of this study, we examined the upper airway anatomy, trachea and main bronchi, and then prepared the instrument to be safely inserted into the trachea. The internal diameter of the trachea was 4-5 $\mathrm{mm}$. The external diameter of the bronchoscope was $3 \mathrm{~mm}$. In the present study, the bronchoscope was gently slid along the trachea. It was crucial not to damage the mucosa of the trachea during bronchoscopy, which was later also confirmed by histopathological examinations. As was stated in our article, bacterial translocation occurred from the damaged intestinal mucosa, not the tracheal mucosa.

In conclusion, the merit of our study is that it addresses the phenomenon of bacterial translocation in the specific settings of bronchoscopy. Bronchoscopy leading to impairment of arterial blood gas parameters may induce intestinal mucosal barrier dysfunction and bacterial translocation. However, further investigations aimed at understanding the clinical consequences of this phenomenon are warranted.

\section{A. Nayci*, S. Atis ${ }^{\#}$}

Depts of ${ }^{*}$ Paediatric Surgery, and ${ }^{\#}$ Chest Diseases, Mersin University School of Medicine, Mersin, Turkey.

\section{References}

1. Nayci A, Atis S, Talas DU, Ersoz G. Rigid bronchoscopy induces bacterial translocation: an experimental study in rats. Eur Respir $J$ 2003; 21: 749-752.

2. Saarnivaara L, Tarkkanen $\mathbf{J}$. The effect of instrumentation with a telescope during bronchoscopy on arterial oxygen tension and acid-base balance. Acta Anaesthesiol Scand 1983; 27: 242-244.

3. Godden DJ, Willey RF, Fergusson RJ, Wrigth DJ, Crompton GK, Grant IW. Rigid bronchoscopy under intravenous general anesthesia with oxygen Venturi ventilation. Thorax 1982; 37: 532-534.

4. Mathisen DJ, Grillo HC. Endoscopic relief of malignant airway obstruction. Ann Thorac Surg 1989; 48: 469-473.

5. Rah KH, Salzberg AM, Boyan CP, Greenfield LJ. Respiratory acidosis with the small Storz-Hopkins bronchoscopes: occurrence and management. Ann Thorac Surg 1979; 27: 197-202.

6. Prakash UB, Diaz-Jimenez JP. The rigid bronchoscope. In: Prakash UB, ed. Bronchoscopy. Philadelphia, LippincottRaven, 1997; pp. 53-69.

\title{
Inflammatory response phases and their hypothetical trophic meaning
}

\section{To the Editor:}

A recent review by WooD et al. [1] emphasises the role of oxidative stress, specifically lipid peroxidation, in the pathophysiology of asthma.

We have also found that oxidative stress is involved in the pathophysiology of post-traumatic inflammation [2-4]. In order to integrate the different alterations that are produced after injury by mechanical energy, we consider that a response based on the successive functional predominance of the nervous, immune and endocrine systems would be produced. This hypothesis implies that the final and prevalent functions of these systems may represent the consecutive phases of the response to stress and all of them could have a trophic meaning.

Considering that these functions are expressed by the endothelium and, thus, by extension, by the vascular wall, the post-traumatic local inflammatory response could be divided into three phases. The first one is a nervous or immediate phase, with vasoconstriction and vasodilation that lead to the ischemia-reperfusion phenomenon. This, in turn, causes cellular oedema (ischemia) and interstitial oedema (reperfusion). The second phase is an immune or intermediate one, which is the cause of diapedesis or cell migration, especially of neutrophils 
and macrophages, and which is associated with coagulation and bacterial infiltration of the injured tissue. Finally, there is an endocrine or late phase characterised by proliferation with endothelium and vascular wall modelling (angiogenesis), which, in the case of healing, involves tissular regeneration or wound healing by scar formation [2-4].

Therefore, in an early or nervous phase, the nutrition of the injured tissue would be produced by diffusion (oedema), a mechanism with low energetic requirement that does not require oxygen (ischemia) or that is not correctly used (synthesis of reactive oxygen species (ROS)). Products derived from the degradation of macromolecules by the ROS action can constitute substrates that reach the cells by diffusion. In the intermediate or immune phase, the nutrition could be mediated by the inflammatory cells because both the neutrophils, as well as the macrophages, have a large capacity for intracellular (phagocytosis of debris) and extracellular (release of enzymes) digestion [5, 6]. Complex proteins, such as enzymes and debris, can be important sources of fermentation [7]. These inflammatory cells respond with respiratory burst and release high concentrations of superoxide anion radical, hydroxyl radical, hypochlorus acid, hypobromite and hydrogen peroxide [1]. The lymphatic circulation could predominate in these phases of the inflammation in detriment of the blood circulation. Finally, in the late or endocrine phase, blood circulation is involved in the nutrition [5, 6]. Angiogenesis makes it possible to acquire a capillary network that is specialised in supplying oxygen and substrates to cells, which, in turn, use them through oxidative metabolism [6, 8], thus producing regeneration. However, the wounds heal by scar formation, a process in which the fibroblasts, due to their phenotypic plasticity [9], could become intermediary cells of the epithelial nutrition. The deficient capacity of the fibroblasts for this trophic function could explain the defective quality of the epithelium obtained.

Phases that are similar to the above-mentioned ones are commonly described in airway asthmatic inflammation [1,9]. In this way, reactive oxygen species hyperproduction, whether by revascularisation or by reactive oxygen species release by the inflammatory cells during the respiratory burst, could represent primitive trophic mechanisms, which are used by the injured tissue when the use of oxygen by oxidative phosphorylation is not possible. More useful energy (adenosine triphosphate) can be generated through this latter pathway and it is a more elaborated trophic mechanism.

\section{M-A. Aller*, J-L. Arias" ${ }^{\#}$ J. Arias* \\ *Surgery Chair, Surgery I Dept, Complutense University of Madrid, and "Psychobiology Dept, Psychology School, Uni- versity of Oviedo, Principality of Asturias, Spain.}

\section{References}

1. Wood LG, Gibson PG, Garg ML. Biomarkers of lipid peroxidation, airway inflammation and asthma. Eur Respir $J$ 2003; 21: 177-186.

2. Lorente L, Aller MA, Arias JL, Arias J. Complement: a cascade with neuro, immune and endocrine functions (letter). Transplantation 1996; 61: 1424-1425.

3. Lorente L, Aller MA, Arias JL, Alonso MS, Arias J. Clinical biology of nitric oxide (letter). Br J Surg 1996; 83: 10101011.

4. Aller MA, Arias JL, Lorente L, Nava MP, Durán HJ, Arias J. Neuro-immune-endocrine functional system and vascular pathology. Med Hypotheses 2001; 57: 561-569.

5. Lawrence WT. Physiology of the acute wound. Clin Plastic Surg 1998; 25: 321-340.

6. Monaco JL, Lawrence T. Acute wound healing. An overview. Clin Plastic Surg 2003; 30: 1-12.

7. Bengmark S. Pre-, pro- and symbiotics. Curr Opin Clin Nutrition Metab Care 2001; 4: 571-579.

8. Lingen MW. Role of leukocytes and endothelial cells in the development of angiogenesis in inflammation and wound healing. Arch Pathol Lab Med 2001; 125: 67-71.

9. Davies DE, Wicks J, Powell RM, Puddicombe SM, Holgate ST. Airway remodelling in asthma: new insights. J Allergy Clin Immunol 2003; 111: 215-215.

\section{Adrenal suppression from high-dose inhaled fluticasone propionate in children with asthma}

\section{To the Editor:}

We read with great interest the paper by Sim et al. [1] who observed adrenal suppression from high-dose inhaled fluticasone propionate (FP) in children with asthma. As adrenal inhibition has also been reported to occur with moderate doses of inhaled FP [2], we recently addressed the question whether low-dose (100 $\mu \mathrm{g}$ twice daily) FP could be associated with impaired adrenal function. For this purpose, 25 children (16 males/9 females) aged 2-12 yrs (mean \pm SD $5.78 \pm 3.1 \mathrm{yrs}$ ) were recruited. All children were affected by moderate asthma and treated with inhaled FP with spacer device for up to 3 months. Early morning cortisol and adrenocorticotrophic hormone $(\mathrm{ACTH})$ levels were determined at the beginning and at the end of the treatment period, after inhalatory therapy had been withdrawn for $\geqslant 24 \mathrm{~h}$. Serum cortisol and ACTH levels were measured by commercially available radioimmunoassay. Data were analysed by paired t-testing and Pearson correlation coefficient. Cortisol levels were significantly higher at the beginning of the treatment period $\left(449 \pm 158.3 \mathrm{nmol} \cdot \mathrm{L}^{-1}\right)$ when compared to the end of therapy (377.4 $\left.\pm 110.8 \mathrm{nmol} \cdot \mathrm{L}^{-1} ; \mathrm{p}=0.01\right)$; one patient presented cortisol levels compatible with complete adrenal suppression $\left(131.8 \mathrm{nmol} \cdot \mathrm{L}^{-1}\right)$ This was associated with significantly higher levels of ACTH at the end of therapy (36.5 \pm 4.3 versus $\left.28.3 \pm 9.5 \mathrm{pg} \cdot \mathrm{mL}^{-1} ; \mathrm{p}=0.01\right)$. No correlation could be found between age and adrenal dysfunction $(\mathrm{p}=0.09)$. The combination of low early morning cortisol levels and high ACTH levels at the end of FP therapy, having withdrawn the inhaled corticosteroid therapy for at $24 \mathrm{~h}$, is highly suspicious of adrenal suppression during treatment with prompt, but partially recovery of the pituitary-adrenal axis once therapy is stopped. Despite the large extent of the adrenal dysfunction, none of the children showed clinical symptoms of adrenal 